\title{
Mind Map and Information Surfing. Unity of Opposites in Education
}

\author{
V.N. Kutrunov,Dr.Sci. in \\ Physics and Mathematics, \\ Professor \\ Algebra and Logic Dep. \\ Tyumen State University \\ Tyumen, Russia \\ kvnkvnkvn@rambler.ru
}

\author{
V.A. Shaptsev, Dr.Sci. in \\ Engineering, Professor \\ Information Systems Dep. \\ Tyumen State University \\ Tyumen, Russia \\ v.a.shapcev@utmn.ru
}

\author{
N.A.Garkusha, Candidate of \\ Pedagogic Sciences, \\ Assistant Professor \\ Department of Foreign \\ Languages and Intercultural \\ Professional Interaction \\ Tyumen State University \\ Tyumen, Russia \\ n.a.garkusha@utmn.ru
}

\author{
L.V.Sizova, senior lecturer \\ Department of Foreign \\ Languages and Intercultural \\ Professional Interaction \\ Tyumen State University \\ Tyumen, Russia \\ l.v.sizova@utmn.ru
}

\begin{abstract}
The article keeps analyzing the impact of the information explosion (IE) on a human ability to absorb information from its current carriers circulating on the Internet. This paper substantiates the inevitable use of Mind Maps (MM) in activating and supporting the thought process as a means of neutralizing the harmful effects of IE. Due to their accessibility and flexibility, MM technologies should be used throughout in educational processes, from early childhood to old age. At the same time, information surfing coexists in the dialectical unity of opposites. This is considered as a tool for the formation of analytical thinking skills.
\end{abstract}

Key words - information surfing, mind map, thinking process, learning, unity of opposites.

\section{INTRODUCTION}

The XXI century is the age of the information society ([1] and others) where a rapid increase in the amount of circulating information is in evidence (and increase in information carriers is more intensive [2]). Today, the number of Information Carriers (InfoC) on the Internet doubles every 1.5 years [3]. Such growth is called information explosion (IE) [4]. Whenever, there was a qualitative change in the forms of storage, processing, and transmission of InfoC, then there was an acceleration of this growth (typography, radio communication, computer and databases, finally, a personal computer and the Internet). Information storage "in the head" has ceased to be dominant since the invention of typography. The ability to remember a lot of information qualitatively (adequately) and quickly weakens with the load reduction on the brain. The amount of InfoC reduces potential time and the desire to think over what they have seen. With "cloud technology", there is a possibility of almost instant access to data (they are numbers, smileys, and video clips). We "glance over" information rather than read and interpret it.

People used to read much more. There is a steady tendency for paper data storage and their transmission as well as text storage and its transmission to disappear. There are already technical assistants being able to deal with InfoC quickly. The term "Artificial Intelligence" (AI) includes InfoC. All this is rapidly improving.
Figuratively speaking, the IE is information space filling with useful, useless, and harmful fragments looking like a mudflow. The way to work with InfoC (data, edocuments, videos, etc.) has changed [5]: the technique of movement of a pedestrian has replaced for the techniques of a rock climber.

The necessity to review all these processes and develop appropriate behavior of individuals and society is obvious. It concerns all spheres of our life. First of all, it entails education because IE injures like any explosion. An individual with his innate (unconditional) reflex "to learn all the available information" is continuously under stress. It is impossible to embrace the boundless. There is a problem (it appears that it is one of the main problems) of the XXI century (an information analogue of the Malthus problem): "the disproportion is between the humankind as the collective producer of information and an individual as its consumer" [4]. We can say that against the background of IE, against the background of the infinity of the information field, the human ability to perceive information (through the interpretation of its carriers) tends to zero. We need a way out, otherwise humankind will be overwhelmed by this flood. We need new pedagogical technologies, starting not with the birth of a child, but with the pedagogical education of future parents, and ending with the last days of the individual. We need safe ways of working with InfoC, ways of developing not only a human, but also safe development of the technosphere intellect, or creating an alternative, i.e. the formation of a new state of humanity (it may be noosphere) and the development of appropriate actions.

This article is sequel to earlier author's articles ([5], etc.). At the same time, our research is presented in the form of Mind Maps (MM) ([6-8] and others) developed in the Free Mind environment [9] (Fig. 1-3) and by means of MS Word (Fig. 4, 5).

\section{UNDERSTANDING THE CONSEQUENCES OF THE INFORMATION EXPLOSION}


MM-1 "Evolutionary consequences of IE" (Fig. 1) is compact and reflects the contents of V. Kutrunov's articles, the idea of which is reflected in the map title. It is necessary to clarify its concepts.

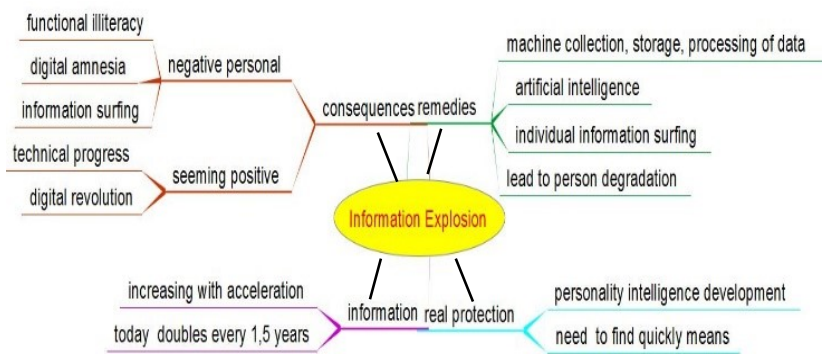

Fig.1. Information explosion consequences (MM-1)

"Digest all the information." This congenital human reflex is impracticable in IE conditions. We need a way out, means of protection.

"Two paths of development." There are two ways to protect against IE. A). It is necessary to create an external environment for the individual to work with InfoC. It should include appropriate philosophy, mathematics, technology, equipment, etc. This environment is called AI. Such an interpretation of AI has a similarity to the noosphere concept in E. Leroy's treatment (for example, [10]). B). The second path is self-improvement of the individual: finding and developing their own (not technical) ways of working with InfoC and information. Actually, there is a third path. It is genetic engineering but it is not considered here.

"The development of AI is paramount." If we do not cope with the information ourselves, we will create AI. Such an environment has undergone a long period of development from abacus to modern AI tools. In this case, it is reasonable to assume that $\mathrm{AI}$ is a complete set of the external to the individual, his consciousness, his thinking, that ensures the processing of InfoC achieving an adequate result.

"Intellectual human self-development" is the second way to protect against IE but it is secondary from the humankind's point of view. Unless the individual is an optimist, this way is impracticable (an information analogue of the problem of Malthus: the human underdevelopment will only grow). Intellectual selfdevelopment in the IE requires a lot of financial investment in education, development of new, considerably deeper and faster teaching methods, technologies to simplify digesting, packaging and transmitting considerably grown information volume to the individual. It is very important. The matter concerns the choice of the future place for the individual. Humanity should not do secondary spots and turn into AI receptors to collect and transmit InfoC to it. However, today the disproportion between investments into $\mathrm{AI}$ and human development is huge.

\section{ABOUT INFORMATION SURFING}

In these conditions, the individual is forced to defend himself against IE. Children are especially vulnerable and in need of protection. They are introduced into an aggressive Information Environment (InfoEn) instead of a human society. Children stay more often and longer there thanks to the encouragement of parents and society believing that InfoEn develops them. Despite the best intentions to make InfoEn friendly, it is aggressive because it is not a human society and therefore it develops in its own way. As a result, we have abandoned children of the XXI century. There is no supervision in the virtual world. The Internet has become a street and an educator for them. There is subculture, closed communities, and dislocations up to murders. All these are against the background of IE. Children are desocialized, i.e., they are more or less removed from a human society. Probably, this is a natural consequence of any leaps in the society development. IE has no mercy on children and they are forced to defend themselves from it. The protection method invented by them is termed Information Surfing (InfoS) by the first author. Something like this has always existed. The older generation knew and applied a "pale" version of this phenomenon, which was called "put the book on a shelf or scan diagonally" but only when it was required. AI is an assistant now. You can refuse to read as there are comics, clips. You refuse to remember as InfoEn and AI remember everything. Children reject difficult or long material: there are "diagonally" abridged and simplified versions. They choose only what leads to "adrenaline". As a result, we obtain such consequences of InfoS as mosaic thinking, digital amnesia, functional illiteracy, drug-like information addiction. These consequences of the InfoS are fixed as conditional reflexes due to active, daily, hours-long stimulation not only in the virtual InfoC, but also in everyday life. They make it almost impossible to deal with individual planning or work as scheduled, concentrate on business for a long time, read long texts, prepare or write coherent material by ear, understand texts and instructions, coherent long speech.

Certainly, the InfoS, which is inevitable now and we have to live with it, has positive aspects. It is necessary to learn how to use them. But being destroyed human abilities are what a student should have a priori when he goes to school and later to university. Their absence made effective training impossible when using the education methods of the last century).

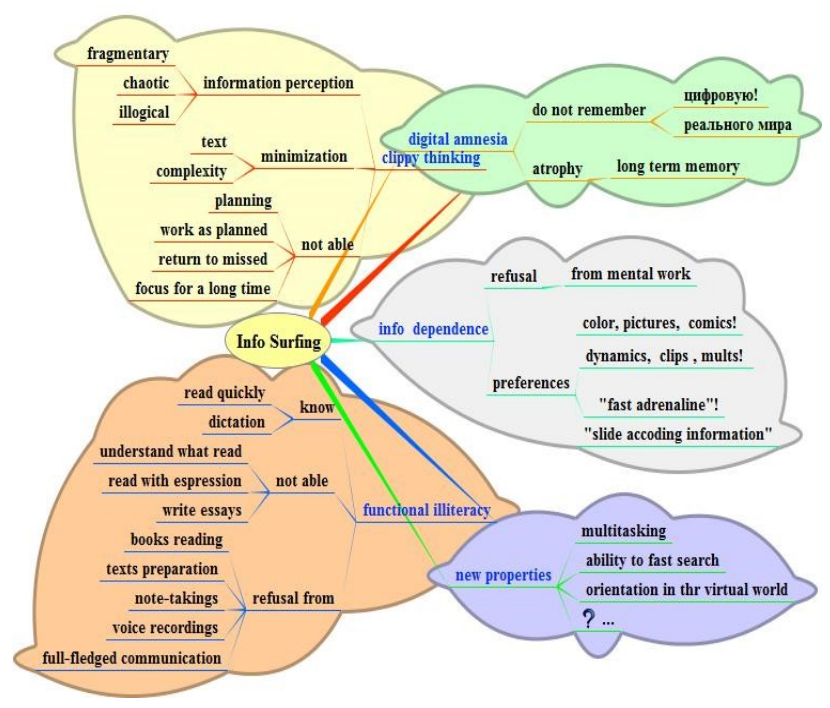

Fig. 2. MM-2: Information surfing

As the figure shows, we have a bifurcation in relation to information: we create AI actively and try to develop ourselves somehow. But we develop ourselves manifold 
weaker than AI. It has a significant impact on young people. Here is the point of view of two people who contributed to the intensive development of AI: "I'm in the camp that is concerned about super intelligence. First, the machines will do a lot of jobs for us, and not be super intelligent. That should be positive if we manage it well. A few decades after that though the intelligence is strong enough to be a concern... I don't understand why some people are not concerned" [11]. Co-founder of Apple Steve Wozniak said, "Artificial intelligence can become a threat to all mankind if experts continue to develop their projects. Sooner or later, thinking machines, conceived to facilitate our lives, will begin to understand that they are better than people. Who will then manage the companies - slow people or machines?" [12]. Note that many high-ranking specialists of Silicon Valley understood the dangers of raising children in virtual InfoEn. They preferred to teach children in Waldorf schools where gadgets were prohibited in and out of school [13].

Is it necessary to defend yourself from it? If the process of AI formation corresponds to the vector of society development, then is AI inevitable? After all, there is a point of view that the form of defense is physical fusion (namely physical), symbiosis of a human and AI. Let's not argue. Let's consider that it is necessary to defend yourself as delegation of thinking ability to AI unloads human brains. In the conditions of brain detraining, there is its atrophy of mental functions, for example, long-term memory. There is a degradation, a transition to the secondary roles after AI and, ultimately, disappearance of humanity. In our case, to defend means to occupy a humanity intellectual niche, those thinking areas that $\mathrm{AI}$ will reach only in years.

In practice, it is necessary to realize the leading role of humanity education and create a tendency: to send the most talented representatives of our society to children; to create such teaching technologies that would interfere with the InfoS and its consequences. It is necessary to collect bit by bit any glimpses of such technologies and do it urgently.

\section{ABOUT TRAINING TECHNOLOGY}

There are many pedagogical technologies, which at first glance seem to struggle with IE consequences. They write about them, defend their dissertations, they use them in experiments. However, the performance level of schoolchildren and students is steadily declining. Something is wrong with technologies. MM-1 suggests the principle of selecting a suitable technology or creating a new one. IE is inescapable. It has established that one of its consequences, namely, the InfoS, causes the greatest harm to the individual, deforming a number of brain abilities. That is, the enemy is identified. The choice, study, modernization or creation of a new pedagogical technology have become relevant now. It is necessary to find an antagonist, pedagogical antipode (neutralizer, antidote) of InfoS. If it is impossible, then at least a certain number of suitable individual pedagogical technologies should be found. As it turned out, the antipode exists and its name is Mind Mapping [6-8].

\section{THE EXPERIENCE WITH THE MIND MAPS}

The antagonism of InfoS and MM is obvious in the MM-2 and MM-3 (Fig.3).

\section{A. About InfoS}

InfoS is a process of continuous movement in InfoEn with rapid random switching, with a preference for short, bright, dynamic (adrenaline) information blocks, with a refusal to establish connections between them, with fixing these actions in the form of a conditioned reflex.

InfoS is the consequence of IE and the acquired human need stimulated by the AI. Quickly to slide and to switch is pleasant, safe in terms of brain overload, energetically profitable. InfoEn provides more and more preferences for such actions. The InelC-2 represents a bouquet of habits the InfoS can create. Not all of them are fixed and it is done at different speeds. Therefore, the injury degree is different for different people. There are some

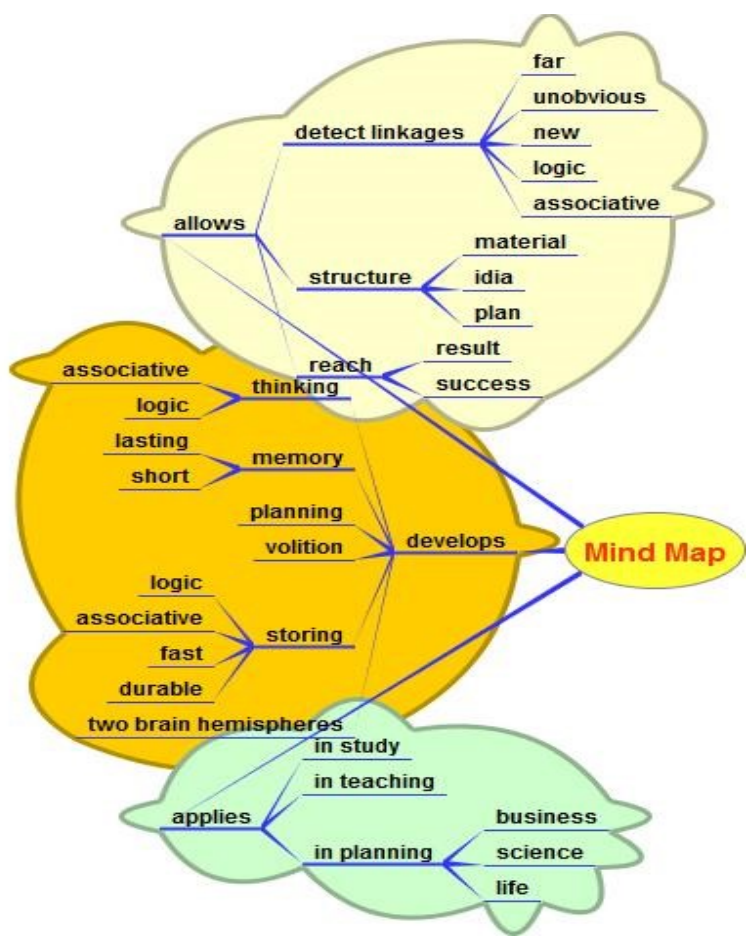

Fig. 3. MM-3: Mind Map potential

uninjured people. To study the reasons of this is interesting. The human has a rational explanation of his behavior, refusing to perform certain actions with information (its carriers). He relies on the belief that he does not need these actions and knowledge for his future well-being. This is the choice of a local optimal trajectory, the choice of an individual trajectory, introduced today in education. With regard to the US, two objections can be given about it. First, the result of such education is "rational ignorance", alien to the Russian spirit and dangerous for the society. Any humanist will say that a rational ignoramus does not know what he is doing. A human should receive the full development of individual personality. Second, the individual often seems to choose the optimal trajectory himself. Everything determines a conditioned reflex called as InfoS it has firmly entrenched. Human actions are not determined by his own will any more. Slipping on information carriers and loss of planning skills, skills of working with information on own accord rule supreme.

\section{B. About MM}

The MMs suppose stops when moving in the InfoEn, and multiple returns to the already passed information 
blocks in contrast to the InfoS. There is a deliberate switch to exactly in-demand topics, long analysis, and then a compact synthesis (in the form of $\mathrm{MM}$ ) of long and complex information fragments. The logical and associative links are established between them and the new is revealed. The individual enjoys the logical-graphic, compact, color display of the thought movement. Mind Mapping offers an iterative process: an almost chaotic collection of media, analysis-compact synthesis, information replenishment accompanied by color graphics, addition of associative links in the absence of accurate knowledge. This is the joint use of logical and associative thinking, the activation of both brain hemispheres and the consolidation of the habit of moving on own accord, according to own plan until complete understanding.

It is easy to see that this process is a natural development of the human mind, the development of the brain. In our context, IntelC is not one of the technologies of brain development, but the process of human thinking. So, the tool has been found. Like AI, it is a prosthesis of the brain, but acts in the opposite direction. It activates the brain by maximizing the disclosure of its resources but not transfer its functions to external InfoEn.

We consider the processes of "building IntelC" and "human thinking" as synonyms. The human thought work is energy intensive, hard, but necessary for the development of his brain, "the world model". The AI presence can make it energetically unprofitable. The individual has to perform this hard work in order to ensure his material and spiritual needs. If the AI starts to provide all of these at lower cost, then the individual will stop developing. It will become an AI appendage, its receptors for the collection and transmission of random media. It is like a correlation between the ant and its brain-anthill. The emergence of InfoS and the creation of AI throw hard work of thinking off humanity. Unpredictable consequences are about to come. It is time to think deeply.

Antagonisms are obvious: Mind Mapping and InfoS, human and AI. However, there is a law of "unity and struggle of opposites". Opposites need each other for effective development. An attempt to destroy one of them is counterproductive because it destroys the other. Now AI develops at great speed. It destroys the thinking of the individual himself. It is necessary to stimulate human thinking actively. The IntelC can become such a tool, the design of which is thinking itself.

It is required to familiarize all people with this statement, IntelC, mental literacy. The IntelC implementation in the XXI century is not an altruistic desire "to implement or not to implement." This implementation is an objective necessity associated with the emergence of an opponent, IS. That said, the question is primarily about education.

\section{Mathematical Mind Maps}

The first author V. Kutrunov is Doctor of Physical and Mathematical Sciences. The second author V. Shaptsev is Doctor of Engineering Sciences. Therefore, the authors develop the practice of Mind Mapping in natural science education. Fig. 4 and 5 are corresponding examples of mental maps. The first example shows the contents of the "Random events" section in the probability theory (MM-4, Fig. 4).
The simplest set of what this section contains is presented in the upper right of the figure. The other three sections of this topic are listed below in the 3 separate blocks. The picture is made in MS Word. Some Mind Mapping support tools allow you to create hypertext, e.g. XMind. When you enter the block, its detailed content appears

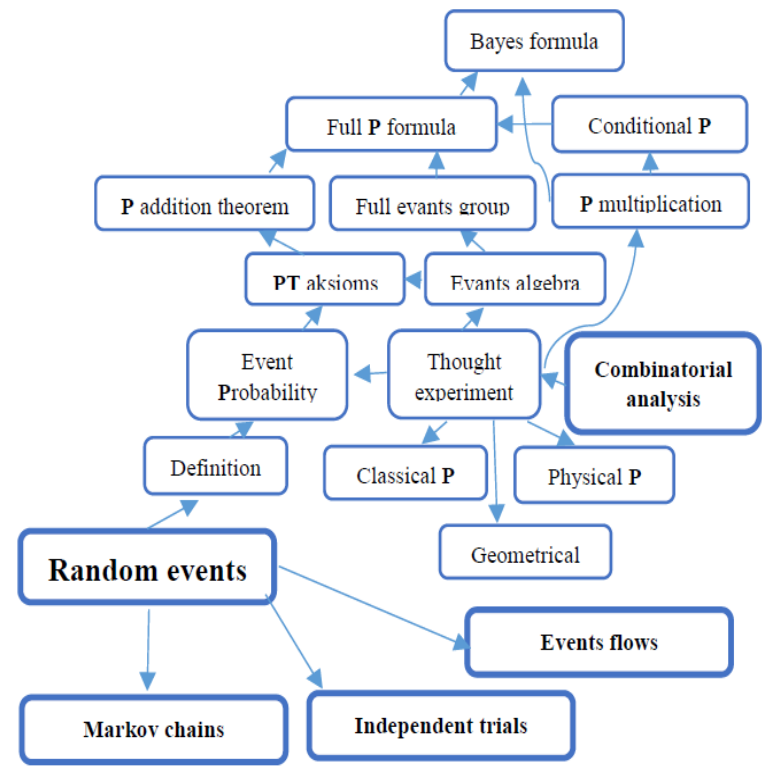

Fig. 4. MM-4: The content of the section "Random events" in probability theory

MM-5 (Fig. 5) is devoted to the assimilation of the conditions of the full probability theorem. Students remember this formula very well but they do not remember the conditions under which it is valid. In the upper right corner of Fig. 5, it is noted that the probabilities are given in terms to the right of the equal sign (theorem 3 condition). Furthermore, each member of the sum is a probability of the product of events $A$ and $\mathrm{H}_{\mathrm{i}}$. Now the event A probability (to the left of the equal sign) is equal to the sum of the $\mathrm{AH}_{\mathrm{i}}$ events probabilities. This means, according to the $3 \mathrm{rd}$ axiom, the fact that $\mathrm{AHi}$ events do not intersect: $\mathrm{AH}_{\mathrm{i}} \mathrm{AH}_{\mathrm{j}}=$ $\mathrm{AH}_{\mathrm{i}} \mathrm{H}_{\mathrm{j}}=\mathrm{H}_{\mathrm{i}} \mathrm{H}_{\mathrm{j}}=\varnothing$. On the other hand, $\mathrm{A}=\Sigma \mathrm{AH}_{\mathrm{i}}=\mathrm{A} \Sigma \mathrm{H}_{\mathrm{i}}=$ $\mathrm{A} \Omega, \Sigma \mathrm{H}_{\mathrm{i}}=\mathrm{A} \Omega$. Then $\mathrm{H}_{\mathrm{i}}, \mathrm{i}=1, \ldots, \mathrm{n},-$ a complete group of events (theorem 2 condition). Condition 1 is obviously: some event A may occur with one of the conditions $\mathrm{H}_{\mathrm{i}}$.

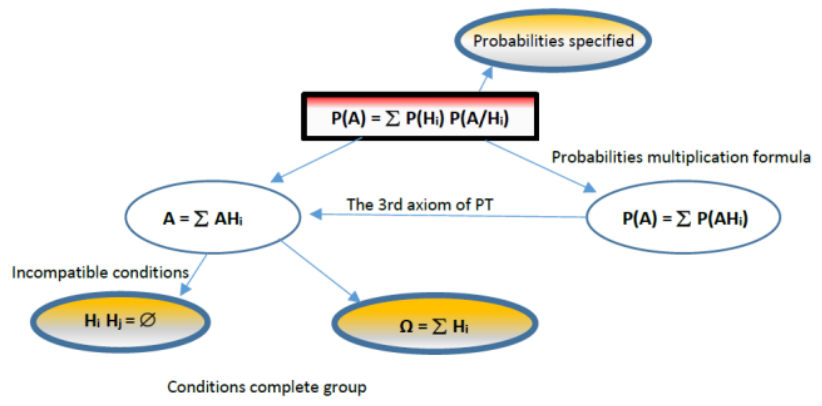

Fig. 5. MM-5: Full Probability Formula on Mind Map

\section{DISCUSSION.}

DO MIND MAPS WORK IN EDUCATION?

If 250 million people are already familiar with Mind Mapping Technology (MMT) in 2000 [7], it is certainly 
being implemented. Some humanists, passionate about $\mathrm{MM}$ introduction into the educational process, write about success. Others think that it is not so simple. Here is one quote. "Regardless of all positive aspects of mental maps, there is no widespread use of them in teaching students, while this tool is the most suitable for the system of higher education" [14].

Here is the statement of one of the MMT creators B. Buzan: "We decided to co-write this book for a number of reasons. ... The third reason was the dissatisfaction. I felt it because all my attempts to teach students the technique of mind maps failed. I came to the conclusion that Tony was right saying that people must be taught not just a certain technique or method, but the way of thinking. Therefore, I wanted to have a book that I could give to a human and instruct him, "It will teach you to think and work, at least like I do" [7]. B. Buzan with students did not happen. His brother T. Buzan gave him advice: "We should teach the manner of thought." This raises a number of questions. What is the difference between "the way of thinking" and "thinking"? There are no publications about the way of thinking. The thinking and the way of thinking seem to be the same. Then, the question arises, what to put before, the cart or the horse? In other words, we need MMtechnologies to develop thinking. However, in order to take advantage of this technology, this thinking should already be. The contradiction is obvious. It is necessary to think over its resolution in order to solve the most important problem of the introduction of Mind Mapping technology into the learning environment. Here is one of such solution.

There is another answer to B. Buzan's question. The problem has been formulated in the book [7] 26 years after the publication of his book "Use Your Head". T. Buzan writes in the preface, "Artificial intelligence appeared on the stage in the early 1970s. The time came when I could buy a computer with a hard drive capacity... ." This could happen in Russia only in the 1990s. Note that Western society evolved in the context of general computerization and the Internet much earlier than Russia. Western youth experienced the conditioned reflex InfoS much earlier with all the ensuing consequences. They have come to the study of B. Buzan since about 1995. Such Russian students came to universities in 2005-10. To master MM, they had to plan, focus on the goal, be persistent, have the opportunity to return to the information flow, have the desire and be able to see unity in disparate information. However, these qualities disappear when you master the InfoS. The paradox is that the older generation assimilates Mind Mapping, and the younger one does not want and cannot. Here is the 2-d answer.

Now we need to use new abilities of young people such as to work in multitasking mode, to find the given information block quickly, their craving for color and compactness. This is in Mind Mapping. Therefore, "the overall structure outlines began to take shape gradually, and, having gained the first confidence in myself, as a hobby, I started helping schoolchildren and college students, who once for various reasons were categorized as "unable to study", "hopeless", "incapable of reading, "backward", and "hard-to-learn". All these so-called griefchildren soon reached a normal level in school, and some became real honors pupils" [6]. Definitely, we talk about the youth of the 70"s, who had not been exposed to IW yet.
There was still no such powerful virtual InfoS during that period, and the youth was not under information attacks. T. Buzan dealt with the young people prepared in a different way. He could not give a good recipe to his brother B. Buzan.

The current students are subjected to the IE. There are new conditions of education. They are in power of InfoS. Scientific thought has not stood still either. Educational technologies have also developed. They did not use our article terms such as IE, InfoS, etc., but you can see the elements of solving the B. Buzan's problem. We will touch on one of the latest works of the Russian Pedagogical School. "The means of logical-graphical structuring and information visualization used for graphical representation of knowledge (for example, representation cards as a semantic links picture of the completed learning material), are a didactic tool of the developmental teaching". S.N. Degtyarev uses the notion of a divergent map. "The divergent map is a graphical representation of the acquired knowledge, logical and its associative connections. It has a nodal structure and is actualized by the central concept (notion, issue, problem)." As a matter of fact, this is MM. "The idea (emphasis added) was born to offer semifinished diagrams and maps containing the basis of the structure of the learning material and the logical scheme of its development. The students finalize the content of the diagrams and maps on their own. Such diagrams and maps are called reference diagrams based on the specified structure and test cards" [15].

The idea of semi-finished diagrams is good in many respects and primarily because it looks simple. For this reason, it can be developed in a ways variety. Two discrete steps have been noted in the approach. First, the teacher draws the map to some degree of readiness that allows the learner to complete it. A few steps can be taken. In this case, the teacher and the student draw individual fragments of the map in turns. The teacher joins when due to lack of knowledge the student is unable to complete the map or makes a mistake. Maps development evokes pleasure.

Group work on the map is a good idea because each participant has it like a semi-finished diagram. Everyone joins when he sees that he can insert his piece of information into it. At the same time, participating in group discussions and disputes about various aspects of the map, the whole group is trained at the expense of each other's knowledge, by thinking and compacting knowledge to invest it in the map, through multiple pronouncing. The latter means that the group map construction activates the thinking-speech connection that should be supported today as well as associative thinking provided lack of information.

In the presence of the destructor of thinking, the habit to create maps (in fact, thinking) should be inculcated in children not only in all disciplines, but also in the solution of difficult vital tasks. Therefore, parents need to study how to create maps as well.

The described method of controlling InfoS with the help of an antagonist in the form of maps is a special case of some general approach. Entering university students should be prepared. Therefore, at school, they have to master the MMT (thought process). Periodically, there are publications about the teachers implementing these 
technologies in schools. They are only enthusiasts. Some examples confirm this statement [15]. InfoEn amazes people as early as their youth. Therefore, it is necessary to pay attention to pre-school education and develop preschoolers' thinking. At present, it is done without MM as children cannot write. Therefore, we need the latest theory and practice of MM for them.

The child's brain organizes clusters of colors, sounds and images from the first day (or even before birth). Therefore, this approach corresponds to its internal needs, its way of thinking, it will not cause rejection and will quickly assimilate. The problem is in adults. Can we develop Mind Mapping technology for the little ones which does not contradict their needs and abilities? Perhaps, it has been developed. This technology will help to preserve the genius of the newborn, it would be good to old age. In any case, they will come to school with the beginnings of a habit to think about their actions, to see them in large blocks, to plan, to depict all these with pictures, and the school will continue to consolidate these habits.

\section{CONCLUSION}

It follows from what has been said above that the development and implementation of Mind Mapping has ceased to be an altruistic desire. If there is a universal InfoS, the antagonist to thinking, then Mind-Mapping has turned into an objective necessity. It should be introduced into educational process from early childhood to old age. The simplicity of the MM idea, its universality almost does not require expenses. It can be implemented in every kind of activity, in every educational discipline. This is seen as a tool for the formation of analytical thinking skills, too.

MMT should become an aid of mastering the disciplines of the program "Healthy lifestyle", including healthy thinking.

The theory and practice of Mind-Mapping should appear for children. Here is the business idea: children should get games that allow them to build and plan graphically, stop, think, design, order, experience the happiness of victory when they have managed to build and implement a graphic plan.

It is necessary to be careful to create some MM base. Some textbooks can be structured through MM placed in the introduction and at the beginning (end) of each chapter.

Finally, electives should be organized for both teachers and schoolchildren of all ages right now. This is the only way to ensure balanced and accelerated development of human and artificial intelligence in dialectical unity and struggle.

\section{REFERENCES}

[1] A.N. Shvetsov, «Information Society». Moscow, URSS, 2012. 280p.

[2] V.A. Shaptsev, Yu.V. Bidulya, Information Theory: Theoretica Foundations of the Information Society. Moscow, URAIT. 2016. 177p. - URL: http://biblio-online.ru.

[3] IDC: the Amount of information on the Internet doubles every year and a half. URL: https://www.securitylab.ru/news/379852.php.

[4] M.N. Epstein, The informational explosion and the postmodernism trauma. 8.10.1998. URL: http://old.russ.ru/journal/travmp/98-1008/epsht Oh.htm (06.02.2017).

[5] V.N. Kutrunov Civilization and dentures. On the question of modern education technologies. Mathematics and information technologies in science education. Tyumen: Publishing house Tyumen State University. 2014. pp. 166-191.
[6] T. Buzan, The memory Cards. Use your memory 100\%. Moscow. Rosmen-Press, 2007. 96p.

[7] T. Buzan, B. Buzan, Supermind. Minsk: LLC "Popurri", 2003. 304p.

[8] H. Muller, Preparation of mind maps. The Ideas generation and structuring Method. Moscow. Omega-L, 2007. 126p.

[9] Mind Mapping or how to make your brain work better. URL: https://habrahabr.ru/company/devexpress/blog/291028.

[10] E. Leroy, Noosphere of the XXI century. URL: http://SocioNauki. ru>almanac/noo21v/number_2/1_1_2.php.

[11] Birds in winter: to feed or not? URL: https://www.msk.kp.ru/ daily/25636/801583/.

[12] Co-founder of Apple: Superintellect is a threat to civilization. URL: https://forbes.kz/process/technologies/on_znaet_kak_vam_luchshe

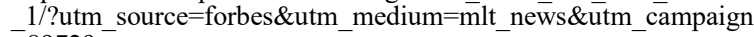
$\equiv 89729$.

[13] A Silicon Valley School That Does n't Compute.

[14] V.A. Litvinov, L.G. Proskurina, Mental maps application in the educational process. Orenburg: OSU. URL: http://gozda.ru/litvinov -v-a-proskurina-l-g .

[15] S.N. Degtyarev, Developing creatively oriented training: design and implementation in high school. Diss. Avtoref. on competition Dr of EDS. URL: http://vak.ed.gov.ru/az/server/php/filer.php?table=att_ case\&fld=autoref\&key[] $=211679$. 